\title{
"The Italian Job": Approaching and Tackling Diffuse Soil Pollution in the EU and the Italian Context
}

\author{
Paolo Bevilacqua \\ Associate Professor, Department of Engineering and Architecture, University of Trieste \\ paolo.bevilacqua@dia.units.it \\ Matteo Fermeglia \\ Ph.D. Student in Legal Sciences, University of Udine and University of Trieste \\ fermeglia.matteo@spes.uniud.it \\ Luca Toneatti \\ Research Fellow, Department of Engineering and Architecture, University of Trieste \\ luca.toneatti@dia.units.it \\ Salvatore Dore \\ University of Trieste \\ salvatore.dore@amm.units.it
}

\begin{abstract}
Diffuse soil pollution is an example of damage caused by human activities and can be understood in the urban context as a combination of causes due to the presence of various and multiple sources of contamination, such as: car traffic, industrial activities and heating. Importantly, the steadfast expansion of city districts over time has brought either industrial activities to enclose residential areas or (although in a few cases) neighborhoods to envelop previously highly industrialized areas. In Italy, both phenomena represent a widely acknowledged reality, e.g., the municipalities of Taranto and Trieste.
\end{abstract}

\footnotetext{
* The article, although jointly discussed by all authors, can be attributable as follows: Prof. Bevilacqua authored Section 3 and co-authored Section 5; Dr. Fermeglia authored Section 2, co-authored Section 1 and Section 5; Dr. Toneatti authored Section 4; Dr. Dore co-authored Section 1. The usual disclaimer applies.
} 
Yet, despite the widespread awareness of the impact of this form of pollution on natural resources and human health, EU environmental legislation depicts an overall picture of fragmentation and poor coordination. Thus, Italian local administrations are striving to devise appropriate methodologies and planificatory measures to bridge such regulatory gap and ultimately find an adequate and comprehensive solution to the problem.

\section{Keywords}

Diffuse pollution - Remediation - Italian Environmental Law - Soil protection

\section{Introduction}

Whilst soils deliver a multitude of functions and ecosystem services to society, they are also subject to various pressures and threats. According to European Environmental Agency, as of 2011 soil contamination affected more than 342.000 sites throughout Europe. ${ }^{1}$

From a normative standpoint, diffuse pollution might well be defined as the truly non-point source contamination, together with the myriad of (individually minor) point sources capable of delivering significant contamination to a given environment. ${ }^{2}$ Furthermore, assessing diffuse pollution proves extremely burdensome since it cannot be subject to prior authorization, ${ }^{3}$ and pollutants' emissions and discharges cannot easily be measured in terms of effluent limitations, as it is unclear who the actual polluter might be. ${ }^{4}$ On top of these already challenging issues, soil protection entails crosscutting aspects, as different environmental and socio-economic pressures and governance conditions across Europe.

Given this backdrop, it is not surprising that many different policy instruments exist at EU and Member States (MS) level, which either explicitly address soil threats or functions, or implicitly display some means of soil protection. ${ }^{5}$ However, such fragmentation is evidently jarring, given the powerful role law can play to manage and ultimately tackle diffuse pollution either in terms of setting standards or design requirements, putting in place frameworks for economic incentives or

\footnotetext{
${ }^{1}$ European Environmental Agency, Progress in management of contaminated sites, 2014.

${ }^{2}$ N.S. Campbell et al., Diffuse Pollution: An Introduction to the Problems and the Solutions, 2004, pp. 2-3.

3 Case C-232/97, L. Nederhoff \& Zn. v Dijkgraaf en hoogheemraden van het Hoogheemraadschap Rijnland [1999] ECR I-06385, para. 40.

${ }^{4}$ R.C. Ferrier et al., Diffuse Pollution - What is the Nature of the Problem? Water and Environment Journal 2005 (4), p. 361,362 .

${ }^{5}$ A. Frelih-Larsen et al., Updated Inventory and Assessment of Soil Protection Policy Instruments in EU Member States. Final Report to DG Environment, 2017.
} 
enabling stakeholders participation in policy developments. ${ }^{6}$

Moreover, the matter at hand requires management, technological and educational approaches. Hence, the absence of a specific benchmark set by the law imposes an innovative engineering approach to be adopted in the presence of diffuse pollution. Relevant, such paths of intervention are consistent with the ones already embedded in other disciplines, such as fire prevention, in which the role of the consultant and an ad hoc design of intervention are increasingly gaining ground as opposed to the mere compliance with parameters and standards set out by regulations.

This article firstly presents an in-depth analysis of the European and Italian regulatory framework on diffuse soil pollution. Next, it indicates the approach used on contaminated soils in Italy, while explaining the crucial differences between point source and diffuse pollution. Lastly, it sheds a light on the Friuli-Venezia Giulia's Regional plan for diffuse soil pollution as a case study, thus highlighting the methodological underpinnings thereof in the peculiar context of heavily urbanized areas, and more specifically in the municipality of Trieste.

\section{The Legal Framework on Diffuse Soil Pollution: Between Ambitions and Uncertainties}

\subsection{EU Law on Diffuse Soil Pollution}

Articles 3 TEU and 191 (1) TFEU foster a Union policy for the preservation of the quality of the environment through a prudent use of natural resources, while protecting human health and dealing with worldwide environmental problems. Although such policy should not be deemed as purely anthropocentric, ${ }^{7}$ it is " $[. .$.$] obvious that the protection of human life and health when threatened by$ external environmental factors and hazardous activities is a subject for environmental policy". 8

As a matter of fact, soil is widely recognized as a valuable source of ecosystem services in the light of $\mathrm{EU}^{9}$ and $\mathrm{UN}$ environmental policy. ${ }^{10}$ Yet, the threat to natural resources and human health posed by diffuse soil pollution (especially in urban areas) appears to constitute an utterly overlooked problem from a regulatory perspective. ${ }^{11}$ In fact, notwithstanding the apparent need for a

\footnotetext{
${ }^{6}$ S. Hendry \& A.D. Reeves, The regulation of diffuse pollution in the European Union: science, governance and water resource management, International Journal of Rural Law and Policy Occasional Paper Series 2012, pp. 1-2.

${ }^{7}$ G. Van Calster \& L. Reims, EU Environmental Law, 2017, pp. 8-9.

${ }^{8}$ D. Langlet \& S. Mahmoudi, EU Environmental Law and Policy, 2016, p. 35.

${ }^{9}$ EEA, SOER 2015 European Briefing: Soil, 2015, pp. 1-2. See also L. Greiner et al., Soil function assessment: review of methods for quantifying the contribution of soils to ecosystem services, Land Use Policy 2017 (69), p. 224; K. Adhikari \& A.E. Hartemink, Linking soils to ecosystem services - A global review, Geoderma 2016, p. 101.

${ }^{10}$ The EU has commited itself to the 2030 UN Sustainable Development Goals. In particular, SDG n.15 on land use includes a pledge to stop land degradation and substantially reduce the number of deaths caused by soil pollution and contamination, all by 2030.

${ }^{11}$ B. Vanheusden, The Relation between Spatial Planning Law and Soil Remediation Law, JEEPL 2010 (1), p. $25,27-$ 28.
} 
comprehensive and coherent regulatory framework, from the very outset EU environmental law on diffuse pollution and soil protection have shown remarkable deference to MS' actions according to the subsidiarity principle. ${ }^{12}$

At the secondary level, EU $7^{\text {th }}$ Environment Action Programme (2014-2020) on the one hand apparently embraces the fight against soil degradation and contamination, therefore calling for a strengthened regulatory setup. ${ }^{13}$ On the other, it points to soil pollution neither as a direct and imminent threat to public health nor as a primary element to enhance sustainability in the urban environment. $^{14}$

Yet overall, the issue of soil contamination can be found scattered in the acquis. Although soil contamination already constitutes a major environmental concern in Europe, there is no EU legislation on management and remediation of Brownfields and, more generally, of contaminated sites. ${ }^{15}$ However, as of 2017, 35 EU legal instruments have been identified as relevant for soil protection either from a regulatory or liability perspective. ${ }^{16}$ Narrowing further the scope of inquiry, provisions potentially addressing diffuse soil pollution in the urban environment are embodied in the following pieces of EU legislation: the 2006 Soil Thematic Strategy (STS) ${ }^{17}$; the Water Framework Directive (WFD) ${ }^{18}$; the Nitrates Directive (ND) ${ }^{19}$; the Industrial Emission Directive $(\mathrm{IED})^{20}$ and the National Emissions Ceiling Directive $(\mathrm{NECD})^{21}$; the Framework Directive on Waste (FDW) ${ }^{22}$; the Environmental Liability Directive (ELD). ${ }^{23}$

The 2006 STS, developed under the $6^{\text {th }}$ Environmental Action Programme, still constitutes the most comprehensive document on soil protection in the EU. ${ }^{24}$ Relevant, it characterizes diffuse contamination as a serious process channelling soil degradation, moreover stressing the potential

${ }^{12}$ G. Van Calster, Will the EC get a finger in each pie? EC law and policy developments in soil protection and brown fields redevelopment, JEL 2004 (1) p. 3, 15 et seq.

${ }^{13}$ Parliament and Council Decision 1386/2013/EU on a General Union Environment Action Programme to 2020

"Living well, within the limits of our planet", OJ 2013 L354/171, Annex, para. 24.

${ }^{14}$ Id., Priority Objective 8, Sustainable Cities: Working together for Common Solutions, paras. 90 et seq.

15 Thus leading to a wide array of solutions among EU MS: see on this point B. Vanheusden, Brownfield Redevelopment in the European Union, Boston College Environmental Affairs Law Review 2007 (3) p. 559 et seq.

${ }^{16}$ Frelih-Larsen et al., supra note 5 at p. 21.

${ }^{17}$ Commission Comunication COM (2006) 231 final, Thematic Strategy for Soil Protection.

${ }_{18}$ Parliament and Council Directive 2000/60/EC etablishing a framework Community action in the field of water policy, OJ $2000 \mathrm{~L} 327 / 1$.

19 Council Directive 91/676/EEC concerning the protection of waters against pollution caused by nitrates from agricultural activities, OJ 1991 L 375/1.

${ }^{20}$ Parliament and Council Directive 2010/75/EU on industrial emissions, OJ 2010 L 334/17.

${ }^{21}$ Parliament and Council Directive 2016/2284/EU on the reduction of national emissions of certain atmospheric pollutants, OJ 2016 L 344/1.

${ }_{22}$ Parliament and Council Directive 2008/98/EC on waste, OJ 2008 L 312/3.

${ }^{23}$ Parliament and Council Directive 2004/34/EC on environmental liability with regard to the prevention and remedying of environmental damage, OJ 2004 L 143/56.

${ }^{24}$ European Commission, Question and answers on the Thematic Strategy on Soil Protection, doc. N. MEMO/06/341, 2006, p. 5. See also C. Olazábal, Overview of the Development of EU Soil Policy: Towards a EU Thematic Strategy for Soil Protection, JEEPL 2006 (3), p. 184. 
detrimental impacts of direct exposure to soil contaminants (e.g., in public playgrounds). ${ }^{25}$ Hence, for soil contamination STS paves the way to National Remediation Strategies (see Figure 1), which shall map out contaminated sites throughout MS, thus aiming at reducing risk and enhancing remediation.

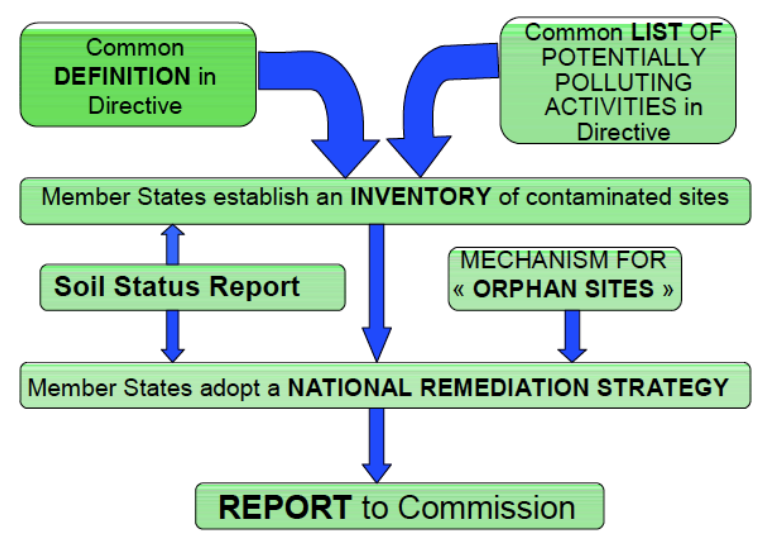

Figure 1. STS National Remediation Strategy. Source: STS

The following Proposal for a Soil Framework Directive ${ }^{26}$, meant as the major legal instrument to craft a prescriptive set of rules on prevention, risk assessment and remediation of soil contamination was ultimately withdrawn in $2014 .^{27}$ Thus, presently any expectation about the EU tackling the issue of soil management and protection, including diffuse soil pollution, under a coordinated and programmatic approach akin to those adopted for waters and waste seems fairly outlandish. ${ }^{28}$

Yet soil protection against diffuse pollution arises as an implicit objective of other disciplines, aimed at setting environmental quality standards for specific natural resources. ${ }^{29}$ Hence, WFD and ND come into play as the first building block of soil protection. Water pollution and soil contamination have been traditionally conceived as strictly interrelated. ${ }^{30}$ Diffuse water pollution sources are mostly indirectly discharged to receiving water bodies, via overland runoff and subsurface flow to surface waters, thus leaching through the soil structure to groundwater. In such regulatory context soil acquires utmost relevance, insofar as it allows for transport of pollutants to

${ }^{25}$ STS, supra note 17 at p. 6. As such, it is identified as comprising: atmospheric deposition; farming practices; inadequate waste and wastewater recycling and treatment. These categories are set out in the Commission Communication COM (2002) 179 final, Towards a Thematic Strategy for Soil Protection.

${ }^{26}$ Parliament and Council Proposal for a Directive establishing a framework for the protection of soil and amending Directive 2004/35/EC, COM (2006) 232 final.

${ }^{27}$ M. Petersen, Europen Soil Protection Law after the Setback of December 2007- Existing Law and Outlook, EEELR 2008 (3) p. 146, 148 et seq.

${ }^{28}$ On the aspects embedded in the uptake of such approach in the context of air and water quality, see F. Groothuijse \& R. Uylenburg, Everything According to a Plan? Achieving Environmental Quality Standards by a Programmatic Approach, in: M. Peeters \& R. Uylemburg (eds.), EU Environmental Legislation: Legal Perspectives on Regulatory Strategies, 2014, p. 116, 125 et seq.; L. Squintani \& H. van Rijswick, Improving the Legal Certainty and Adaptability in the Programmatic Approach, JEL 2016 (3), p. 443 et seq.

${ }^{29}$ M. Petersen, supra note 27 at p. 152; I.L. Hauser, Milestones of Soil Protection in EU Environmental Law, JEEPL 2006 (3), p. 190, 193; G. Van Calster \& L. Reins, supra note 7 at pp. 206-212.

${ }^{30}$ Commission Comunication COM (2002) 179, supra note 25 at pp. 22-23. 
surface and groundwater bodies. ${ }^{31}$

The WFD is by far the most advanced legislation in terms of establishing a holistic approach to commonly recognized environmental objectives within the EU. ${ }^{32}$ Importantly, WFD relies on the pivotal, yet unclear concept of good ecological status, ${ }^{33}$ which comprises the "quality of the structure and functioning of aquatic ecosystems". ${ }^{34}$ Given this target-oriented setup, WFD follows a combined approach encompassing all sources of pollution. ${ }^{35}$ Furthermore, it envisions diffuse pollution as a major obstacle to the achievement of good status or ecological potential of waters. ${ }^{36}$ According to the WFD, MS are required to put in place specific measures aimed at preventing, prohibiting and monitoring diffuse discharge of pollutants. ${ }^{37}$ Importantly, when implementing the measures listed in the WFD, MS shall even opt for stricter measures, if WFD's environmental objectives for a given body of water (surface or groundwater) are unlikely to be achieved. ${ }^{38}$ Needless to say, the above measures undertaken to fight water diffuse pollution might well include measures addressing soil management, including treatment of soil diffuse contamination. ${ }^{39}$ However, as stated above soil degradation acquires relevance in the light of the WFD as long as it factors into water bodies' quality assessment. ${ }^{40}$

The ND is part of both the WFD and the cross-compliance mechanism under the Common Agricultural Policy. Since agriculture constitutes the major source of water diffuse pollution in the EU, ${ }^{41}$ the ND wishes to establish good farming practices so as to reduce all forms of water pollution by nitrates. ${ }^{42}$ To fulfil such purpose, the ND includes provisions dealing directly with soil protection, whereby MS may take into consideration soil conditions while developing good agricultural practices, ${ }^{43}$ and action programmes for designated vulnerable zones. ${ }^{44}$

The second building block of EU law on diffuse soil pollution can be drawn from the bodies of norms regulating industrial emissions and waste production and disposal.

${ }^{31}$ OECD, Diffuse Pollution, Degraded Waters: Emerging Policy Solutions, 2017, 72 et seq.

${ }^{32}$ Commission Communication COM (2009) 156 final, Report from the Commission to the European Parliament and the Council in accordance with article 18(3) of the Water Framework Directive 2000/60/EU on programmes for monitoring of water status.

${ }^{33}$ S. Hendry, The EU Water Framework Directive - Challenges, Gaps and Potential for the Future, JEEPL 2017 (3-4) p. 249,254 et seq.

${ }^{34}$ WFD, supra note 18, Article 2(21).

${ }^{35}$ Id., Article 10.

${ }^{36}$ W. Howarth, Diffuse Water Pollution and Diffuse Environmental Laws: Tackling Diffuse Water Pollution in England, JEL 2011 (1), p. 129, 132 et seq.; Hendry \& Reeves, supra note 6 at p. 3.

${ }^{37}$ WFD, supra n. 18, Article $11(3)(\mathrm{h})$.

${ }^{38}$ Id., Article 11 (5).

${ }^{39}$ Id., Annex II, V, 1.3; Annex II (V) (2.4); Annex VII (A) (2). See also M. Petersen, supra note 27 at p. 152.

${ }^{40}$ C. Olazábal, supra note 24 at p. 185.

${ }^{41}$ Commission Comunication COM (2015) 120 final, The Water Framework Directive and the Floods Directive: Actions towards the 'good status' of EU water and to reduce flood risks, p. 6.

${ }^{42}$ Case C-258/00, European Commission v. French Republic [2002] ECR I-5959, para. 53.

${ }^{43} \mathrm{ND}$, supra note 19, Annex II.

${ }^{44}$ Id., Annex III, 1(3)(a). Importantly, Annex III calls for rules regarding the concentration of nitrogen in the soil at the moment when it becomes significant for crop's use. 
As for industrial emissions, ${ }^{45}$ the IED widely conceives soil as part of an integrated approach to protect the environment - also recalling the STS and the relevant EU law on soil protection. ${ }^{46}$ Furthermore, it generally addresses diffuse soil pollution, insofar as it subsumes release of substances from diffuse sources into the relevant notion of "emission" for its own purposes. ${ }^{47}$ Hence, the IED provides that environmental permits for industrial activities contain appropriate requirements ensuring protection of soil (and groundwater) in the area of the installation and remediation of contaminated sites, coupled with monitoring and maintenance tools. ${ }^{48}$ In the context of local pollution, control of emissions from stationary sources (i.e., industrial installations) indeed ought to result in a reduction in the overall level of soil contaminants. ${ }^{49}$ However, the definition of installation in the IED is crafted in a very narrow fashion, thus not including off-site activities. ${ }^{50}$ But most importantly, the IED is not a suitable instrument to tackle diffuse soil pollution stemming from a combination of industrial emissions and other urban stationary, as well as mobile sources, such as households heating and car traffic.

Yet, the NECD might hold a relevant role in this respect. It sets emission reduction commitments for major air pollutants, thus encompassing all key acidifying and eutrophying substances affecting soil functions in urban areas. ${ }^{51}$ Furthermore, under NECD MS are required to monitor any negative impacts of air pollution upon terrestrial ecosystems, regardless of its source. ${ }^{52}$ Though the NECD cannot ultimately be regarded as a quite comprehensive tool to regulate diffuse soil pollution, since it is based on a purely programmatic approach, thus leaving MS wide flexibility as to the measures to be adopted. ${ }^{53}$

As for waste, the FDW aims at preventing waste management activity causing land contamination in the light of the principle of preventive action. ${ }^{54}$ Accordingly, waste management and disposal

\footnotetext{
${ }^{45}$ The IED covers inter alia air emissions of sulphur dioxide $\left(\mathrm{SO}_{2}\right)$, nitrogen dioxide $\left(\mathrm{NO}_{\mathrm{x}}\right)$, volatile organic compounds and metals (and their compounds). Id., Annex II.

${ }^{46}$ IED, supra note 20, Recital 4 and Article 22(1). J. Jans \& H.H.B. Vedder, European Environmental Law, 4th ed., 2012 , p. 361.

${ }^{47}$ IED, supra note 20, Article 3(4).

${ }^{48}$ Id., Article 22. See also I. Pilaš \& N. Bakšić, Soil Protection in the EU According to the Directive on Industrial Emissions (IED) and Croatian Practice, SEEFOR 2014 (1), p. 53, 56 et seq.

${ }^{49}$ A. Frelih-Larsen et al., supra note 5, at p. 99.

${ }^{50} \mathrm{~J}$. Sanden, Coherence in European Environmental Law with particular regard to the Industrial Emissions Directive, EEELR 2012 (5), p. 220, 230.

${ }^{51} \mathrm{NECD}$, supra note 21, Article 1 and Annex II. Whilst sulphur dioxide $\left(\mathrm{SO}_{2}\right)$, nitrogen oxides $\left(\mathrm{NO}_{\mathrm{x}}\right)$, non-methane volatile organic compounds (NMVOC), ammonia $\left(\mathrm{NH}_{3}\right)$, fine particulare matter $\left(\mathrm{PM}_{2,5}\right)$ are subject to specific national reduction commitments, other substances such as Benzo(a)pyrene, $\mathrm{PM}_{10}$ and heavy metals shall be part of an annual emission inventory to be submitted by MS by 15 February 2017 and every year thereafter (Id., Article 8 and Annex I).

${ }^{52}$ Id., Article 9 and Annex V. Soil acidity, nutrient loss, nitrogen status and balance, as well as biodiversity loss are listed as basic indicators for monitoring air pollution impacts accordingly.

${ }_{53}$ Cases C-165/09 and C-167/09, Stichting Natuur en Milieu and Others [2011] ECR I-4599, paras. 97-99.

${ }^{54}$ Aside the FDW, relevant bodies of law are also: Council Directive 86/278/EEC on the protection of the environment, and in particular of the soil, when sewage sludge is used in agriculture, OJ 19861 181/6; Council Directive 1999/31/EC on the landfill of waste, OJ 1999 L 182/1; Council Directive 91/271/EEC concerning urban waste-water treatment, OJ 1991 L 135/40.
} 
activities must be carried out without endangering human health and putting at risk natural resources, including soil. ${ }^{55}$ Moreover, soil cleaning and land treatment are envisaged as management and disposal measures, respectively. ${ }^{56}$ Contaminated sites (and remediation plans thereof) might also be taken into consideration by MS waste management plans pursuant to FDW Article $28{ }^{57}$ Yet, the FDW primarily targets soil pollution by waste at their emission source, thus only indirectly tackling diffuse pollution. ${ }^{58}$

Therefore, the ELD arguably stands out as the most effective tool to ensure prevention and remediation of soil contamination, albeit from a liability perspective. As of 2016, more than half cases (747) reported by MS under the ELD had involved soil damage (or threat thereof). ${ }^{59}$ However, land (soil and subsoil) is apparently embraced in the ELD as a self-contained category of protection, but only in relation to the threshold of significant risk for human health. ${ }^{60}$ So, the liability regime laid out in the ELD oddly focuses neither on soils quality nor on soils' functions in a given local environment. ${ }^{61}$

Moreover, the ELD itself generally recognizes liability as an ineffective tool to fight diffuse pollution. ${ }^{62}$ Thus, environmental damage (or imminent threat thereof) arising from diffuse pollution falls out of the scope of the ELD, unless a causal link between the damage and the activities of individual operators can be established consistently with the polluter-pays principle. ${ }^{63}$

\footnotetext{
${ }_{56}^{55}$ FDW, supra note 22, Article 13.

${ }^{56}$ Id., Annex I and Annex II.

${ }^{57}$ Commission DG Environment, Preparing a Waste Management Plan: A Methodological Guidance Note, 2012 , p. 73.

${ }^{58}$ Furthermore, the same FDW does not apply to both unexcavated contaminated and excavated uncontaminated soil: FDW, supra note 22, Article 2(1).

${ }^{59}$ Commission Working Document SWD(2016)121 final, REFIT evaluation of the Environmental Liability Directive, pp. 27-28.

${ }^{60}$ ELD, supra note 23, Article (2)(1)(c). G. Van Calster \& L. Reins, The ELD's Background, in: L. Bergkamp \& B. Goldsmith (eds.), The EU Environmental Liability Directive: A Commentary, 2013, p. 9, 21

${ }^{61}$ M. Petersen, supra note 27 at p. 153 et seq.; G. Winter et al., Weighing up the EC Environmental Liability Directive, JEL 2008 (2), p. 163, 173-174.

${ }^{62}$ ELD, supra note 23, Recital 13. See also BIO Intelligence Service, Implementation challenges and obstacles of the Environmental Liability Directive. Background Document for the European Commission - DG Environment, 2013, 18 et seq. and Commission Working Document SWD(2016)121 final, supra note 59 at p. 10.

${ }^{63}$ Id., Article 4(5). See also Case C-378/08, ERG and others [2010] ECLI:EU:C:2010:129, para. 53; Cases C-478/08 and C-479/08, Buzzi Unicem and others [2010] ECR I-0031, para. 39; Case C-534/13, Ministero dell'Ambiente e della Tutela del Territorio e del Mare and others [2015] ECLI:EU:C:2015:140, paras. 57-59.
} 
Yet the ELD does not prevent MS from adopting domestic provisions expanding the scope of responsible persons. ${ }^{64}$ MS legislation transposing the ELD may hold owners of polluted land jointly liable with its user regardless of the former's actual contribution to the damage, provided that it complies with general principles of EU law (as well as EU primary and secondary legislation) and contributes to enhance the inherent objectives of the ELD. ${ }^{65}$ Importantly, such argument squares with the one allowing public authorities to rely on rebuttable presumption based on installations' proximity to the polluted area when establishing a causal link between operators and diffuse contamination sources, ${ }^{66}$ therefore leading to a relaxation of the ELD enforcement regime on damage stemming from diffuse pollution. ${ }^{67}$

\subsection{Italian Law on Diffuse Soil Pollution}

As a matter of Italian environmental law, the concept of diffuse pollution is spelt out by the rules dedicated to the remediation of contaminated sites in the Legislative Decree no. 152/2006 (LD), Section 4, Title 5. Accordingly, diffuse pollution is defined as either any physical, chemical or biological contamination (or alteration) of natural resources (namely soil, subsoil and groundwaters) resulting from multiple, yet not traceable sources. ${ }^{68}$ As such, diffuse pollution lays outside the scope of the rules on contaminated sites remediation, which therefore apply only in case of (water and/or soil) point source pollution. ${ }^{69}$ Hence, all remediation activities to be carried out in diffusely contaminated sites must draw from site-specific Diffuse Pollution (management) Plans (DPPs), which are developed and locally implemented by Regional administrations. ${ }^{70}$ Nevertheless, DPPs shall abide by the principles governing the set of rules on remediation of contaminated sites. ${ }^{71}$ Thus, from a normative standpoint the latter operates as a general framework, thus informing the planificatory and regulatory setup of the former.

\footnotetext{
${ }^{64}$ ELD, supra note 23, Article 16 (1).

${ }^{65}$ Case C-129/16, Túrkevei Tejtermelő Kft. [2017] ECLI:EU:C:2017: 547, para. 63. V. Fogleman, Study on Analysis of integrating the ELD into 11 national legal frameworks, Final Report for the European Commission - DG Environment, 2013, pp. 76-77. B. Pozzo et al., The Remediation of Contaminated Sites and the Problem of Assessing the Liability of the Innocent Landowner: A Comparative Law Perspective, European Review of Private Law 2015 (6), p. 1071, 1083 et seq.

${ }^{66}$ Yet only in presence of plausible evidence: Case C-378/08, supra note 62, paras. 57-59; Cases C-478/08 and C479/08, supra note 63, paras. 40-42.

${ }^{67}$ F. Goisis \& L. Stefani, The Polluter-Pays Principle and Site Ownership: the European Jurisprudential Developments and the Italian Experience, JEEPL 2016 (2), p. 218.

${ }^{68}$ LD, Article 240, para. 1 (r).

${ }^{69}$ T.A.R. Friuli Venezia Giulia, judgment no. 215/2015, para. 2.3.1.-2.3.2.; Consiglio di Stato, judgment no. 1489/2016, para. 4.

${ }^{70}$ LD, Article 239, para. 3.

${ }^{71} \mathrm{Id}$.
} 
As a consequence though, DPPs face substantial limitations in terms of their scope of application both from a regulatory and liability standpoint. According to Article 239 LD, DPPs shall not take account of largely contaminated industrial sites known as Siti di Interesse Nazionale (SIN), regardless of whether those sites are in fact diffusely polluted. ${ }^{72}$ By the same token, as mere planificatory instruments DPPs shall not lay down any liability regime for remediation of diffuse pollution, instead aiming only at identifying and coordinating remediation actions needed on diffusely contaminated sites. Hence since there is no liability for remediating sites subject to a DPP, Article $250 \mathrm{LD}$ applies whereby if no persons can be held liable for the pollution, then public authorities (i.e., local Municipalities and Regional administrations) must proceed to remediation activities themselves, eventually seeking to redress the costs incurred from the owner(s) of the contaminated site, albeit within the limit of the market value thereof. ${ }^{73}$

Against this background, the LD points out neither how DPPs should be elaborated nor its content. Moreover, one DPP has been adopted thus far, and it does not address diffuse soil pollution. ${ }^{74}$ Yet, a crucial benchmark can be inferred from the general rules on soil protection and soft law instruments purposely adopted to grapple with diffuse pollution.

As for the principles governing remediation of contaminated sites, in the light of the long-standing Italian administrative jurisprudence and doctrinal opinions, one might ultimately understand them as reflecting the general purpose of pursuing and granting an overall acceptable standard of human health through the conservation and protection of natural resources. ${ }^{75}$

Hence, according to Italian environmental law, remediation of contaminated sites shall be conducted consistently with EU principles of environmental law, and more specifically with the polluter-pays principle. ${ }^{76}$ Furthermore, with regard to soil contamination, remediation activities shall aim at bringing contaminated sites back to its adequate use as laid down by local zoning provisions, rather than to its full reparation. ${ }^{77}$

\footnotetext{
${ }^{72}$ Pursuant to art. 252 LD, SIN are largely contaminated sites, either abandoned or still in use ither for industrial of residential purposes, which are deemed as significantly dangerous for human health and the environment. See also infra, para. 3

${ }_{73}$ Article 253 LD. Such provision has been deemed compatible with the EU principles on environmental liability and consistent with MS national legislators' discretion provided for by art. 16 ELD. See case C-534/13, supra note 63; Goisis \& Stefani, supra note 67 at 231 et seq.

${ }^{74}$ Regione Lombardia, Deliberazione della Giunta Regionale 20 giugno 2014, n. 1990.

${ }^{75}$ F. de Leonardis, La bonifica ambientale, in: P. Dell'Anno \& E. Picozza (eds.), Trattato di diritto dell'ambiente, II, 2013, p. 278, 290 et seq.

${ }^{76}$ LD, Article 239, para. 1. M. Benozzo, La bonifica dei siti contaminati, in: A. Germanò et al. (eds.), Commento al Codice dell'ambiente, 2013, p. 664, 667 et seq.

${ }^{77}$ Consiglio di Stato, judgment no. 2128/2017, para. 21.1.
} 
Tacking stock of the several pitfalls and hurdles embedded in addressing diffuse pollution, the Italian Istituto Superiore per la Protezione e la Ricerca Ambientale (ISPRA) has issued national procedural guidelines for the adoption of DPPs. ${ }^{78}$ Reaffirming the above notion of diffuse soil pollution enshrined in the LD, the guidelines envisage a fairly straighforward procedure for the design of the DPPs. In sum, it comprises the following steps:

1. Evidence-gathering about the extension of the polluted area, pollutants' concentration and presence/absence of point source pollution therein ${ }^{79}$

2. Assessment of each detected contaminant's level of diffusion throughout designated areas with regard of both natural (e.g. metals, semi-metals) and human released substances, also in order to cross-reference them with adjacent areas;

3. Drafting of a conceptual model (CM), aimed at ascertaining the presence of the fundamental requirements to proceed with the DPP, in particular the actual apportionment of point and non-point pollution sources; $;^{80}$ furthermore, the CM shall ultimately mark out all relevant diffusely polluted areas, also in order to separate them from point source polluted ones;

4. Thorough verification of both environmental and health risks connected with each identified diffusely polluted area;

5. Defined outlook of DPP's short-medium and medium-long term objectives, as well as remediation and risk-mitigation activities to be undertaken accordingly and pursuant to Article 239, para. 3 LD. ${ }^{81}$

\section{Assessment and Management of Potentially Contaminated and Contaminated Sites in Italy}

On a defined potentially contaminated site, such as the site on which an industrial plant is located, the procedures, methods and analyses for the determination of the possible soil and groundwater contamination are well established by almost twenty years of experience. ${ }^{82}$ Even the correct management of the matrices, in the case the contamination is present, is well known.

\footnotetext{
${ }^{78}$ ISPRA, Criteri per la gestione dell'inquinamento diffuso, Doc. n. 76/16, 2017.

${ }^{79}$ Relevant, in case of soil diffuse pollution, the extent of the identified polluted area shall not be less than $1 \mathrm{~km}^{2} . I d$., at 9.

${ }^{80} I d$., at 10 . The CM shall function as an information-gathering tool with regard to, inter alia: the pedologic, geologic and hydrogeological characteristics of the site; soil and water use; forms, extent and degree of contamination; all the previous and current activities carried out in the contaminated areas. For soil contamination, the CM shall also map out each pollutant's concentration with regard to its relevant threshold.

${ }^{81} I d$., at 14 . Yet importantly, such measures shall be scaled taking into account the possible co-ordination of actions between public authorities and private individuals, as much as their economic viability.

${ }^{82}$ APAT, Manuale per le indagini ambientali nei siti contaminati, 2006.
} 
The Italian legislation also wanted to set out rules on large contaminated industrial sites on the Italian territory, known as Siti di Interesse Nazionale (SIN) pursuant to Article 252, para. 1 LD. These sites are very extensive contaminated areas classified as significantly dangerous by the Italian Ministry of the Environment and which require remediation of soil, subsoil and/or surface and groundwaters to avoid environmental and health damage. The management of these sites is fully handled at the State level.

The difficulties in approaching these sites are greater, due either to the presence of several contiguous industrial areas with different contaminations, or more industrial activities; however, even in this case the Italian experience gained on 52 SIN allows us to state that the metrics for correct management are known.

The case of diffuse soil pollution is very different, as defined by the law and managed by the DPPs. The vast area concerned is not so clearly identifiable, the causes of pollution are not univocally correlated and the surfaces are very large.

As for defined contaminated sites and SIN, the verification of the contamination status begins with the study of the available documents and subsequently with precise analyses (coring, piezometers and sampling at different depths from the campaign surface). This information is then extended throughout the site through interpolations with the aid of interpolation software ${ }^{83}$.

The Italian legislation, first through Ministerial Decree 471/1999 (MD) and later with the LD, has in fact defined the procedures and techniques to be applied in the presence of contamination of soil and / or groundwater.

MD adopted a tabular approach. Accordingly, a site would be deemed contaminated if the degree of pollutants' concentration in soil and/or groundwater samples had exceeded the tabulated values (reported in the MD), thus triggering the reclamation and securing operation.

With the entry into force of LD, the methodological approach was modified by introducing the concepts of potentially contaminated site and risk analysis.

LD, Article 240, para. 1 (d) puts forward the definition of potentially contaminated site: a site in which one or more concentration values of the polluting substances detected in the environmental matrices are higher than the contamination's concentration threshold (CSC), waiting to carry out the characterization operations and of a specific site health and environmental risk analysis, which allow it to determine the contamination status or not on the basis of the risk concentration threshold (CSR);

\footnotetext{
${ }^{83}$ P. Bevilacqua et al., Geostatistics in soil science: a useful tool for soil contaminated sites characterization, Siti contaminati 2003 (1), pp. 30-34.
} 
LD, Article 240, para. 1 (e) in turn clarifies the notion of contaminated site: a site in which the values of the risk concentration threshold (CSR), determined with the application of the risk analysis procedure referred to in Annex 1 to the fourth part of this decree based on the results of the characterization plan, they are outdated.

The new approach introduced by the LD was therefore that of first checking the exceeding of table values (CSC) for the analyzed matrices. If this happens for soil or groundwater (we are therefore in the presence of a potentially contaminated site) it is necessary to apply environmental health risk analysis to the site.

The analysis of health-environmental risk is the tool that allows to quantitatively assess the risks to human health related to the presence of pollutants in environmental matrices. ${ }^{84}$

If the results of this health-environmental risk analysis in terms of concentrations (CSR) are lower than the concentrations determined in the area, the site is deemed contaminated (see Figure 2).

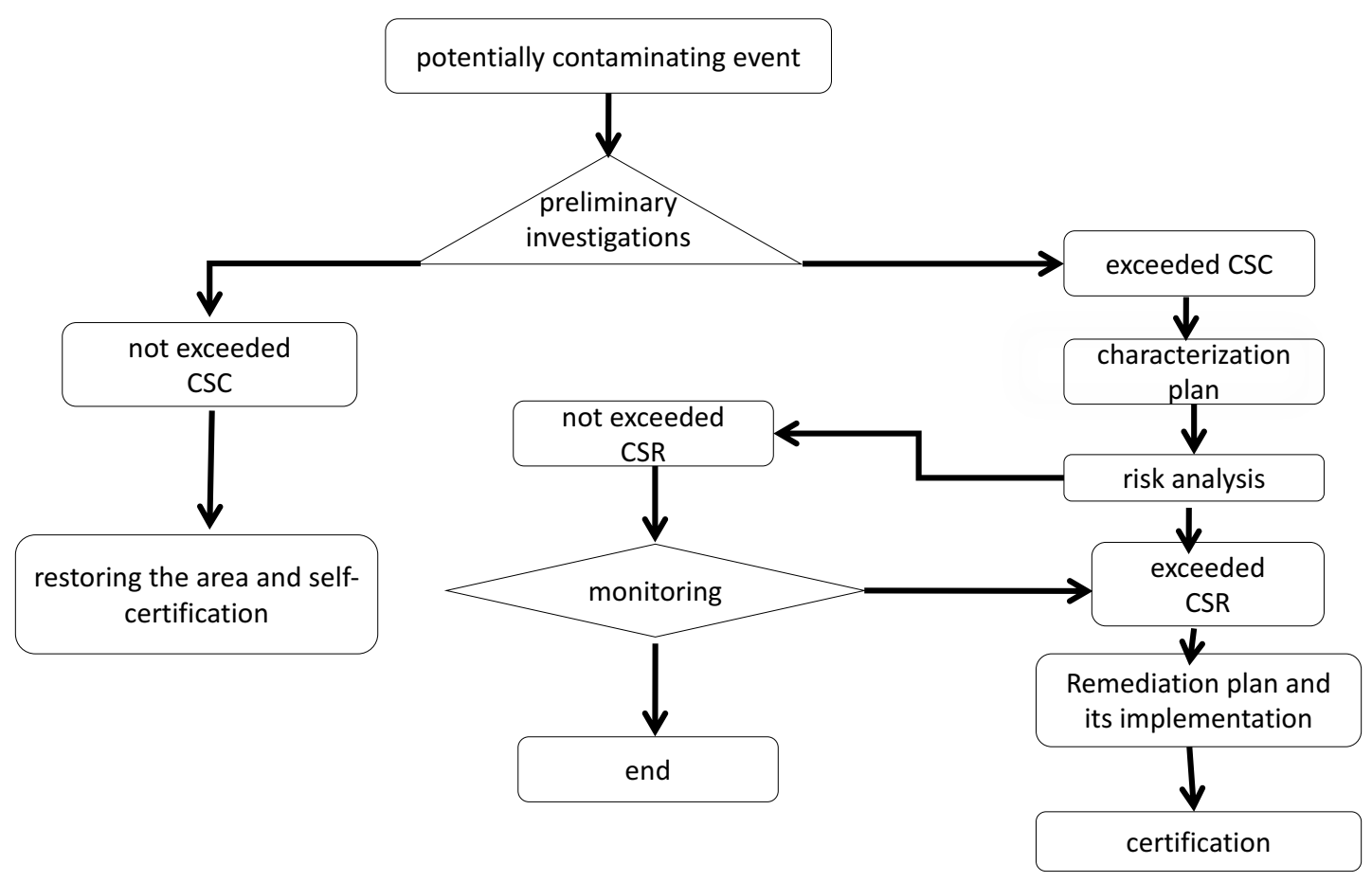

Figure 2. Procedure for the management of contaminated sites. Source: Author

It is therefore necessary to proceed with the reclamation of the site. Reclamation techniques are well known and consolidated for both soil and water, differentiating by type and concentration of the contaminants. It is evident that the technologies for matrix remediation must be economically sustainable. Therefore, reclamation technologies are chosen among the Best Available Technology Not Entailing Excessive Costs (BATNEEC). ${ }^{85}$

${ }^{84}$ ISPRA, Criteri metodologici per l'applicazione dell'analisi assoluta di rischio, 2005.

${ }^{85}$ S. Sorrell, The Meaning of BATNEEC: Interpreting excessive costs in UK industrial pollution regulation, Journal of Environmental Policy and Planning 2001 (1), pp. 23-40. 
In some cases, however, the cost of reclamation might be too high; hence, one can decide either to intervene with permanent securing techniques or to confine the contaminated soil inside a "sealed" structure. It is clear that in this case the land will undergo a downgrading for the purpose of fruition. It is possible to conclude that the experience gained thus far allows us to deal and rigorously resolve every situation in which the contaminated site is defined and the polluting activity of the soil matrix is also known. The water matrix would deserve a separate mention, since being a fluid in motion it can present contaminations that are not univocally correlable with a precise source of pollution.

However, to extend the methodology described above for confined sites to diffuse pollution, is not feasible, both from an economic standpoint and for resaoning on the identification of the person responsible for pollution. It is therefore necessary to address the problem with an innovative approach. Nevertheless, the experience gained in risk analysis can certainly be useful for finding out the new approach to dealing with diffuse soil pollution.

\section{Methodological Approach to Dealing with the Problem of Diffuse Soil Pollution}

Diffuse pollution encompasses some peculiarities that require an innovative approach. First of all, it is necessary to define the parameters that identify the status of the investigated matrix and delimitate the area of interest in a reasoned and motivated way. Only after these first preliminary yet not trivial operations it will be possible to proceed with the process concerning the identification of possible solutions to the problem.

The first question to ask therefore concerns the nature of the substances / contaminants to be analyzed, their variety and their possible interactions with the human being and the environment (health aspects). Defining in a reasoned manner the parameters to be evaluated for the correct description of the situation is a sort of milestone for the whole diffuse pollution management process. Hence, the first step here is the choice of the analytes that can best represent the state of contamination of the matrix both from the merely numerical and mathematical point of view, as much as the consequences that a certain concentration of a selected substance may have for human health and environmental well-being.

The choice of analytes thus have to consider two primary aspects:

1. Human interaction;

2. Effects on the surrounding environment.

In addition, the possibility of identifying new contaminants that can better represent the situation must always be taken into account. However, it is evident that the first point above is of utmost importance in the whole process. 
It should be noted that contamination thresholds in soil and subsoil referred to the specific intended use of the sites to be reclaimed (either for public, private and residential use or sites for commercial and industrial use) are indicated in the annexes to Part V of LD. These values can be taken as an initial benchmark to define the conceptual model concerning the analyzed situation, yet they must be subject to further analysis, which includes the evaluation of the local background's values in terms of both natural and anthropic origin.

In the case of diffuse pollution indeed, the approach cannot be limited to the identification of naturally occurring concentration values. In fact, it must also evaluate any background concentrations caused by man, their impact on the environment and their management, since it is not always possible to simply impose the lowering of the values found due to the diffuse nature of the sources.

The effects on the surrounding environment ought not be either ignored or underestimated, since they play a central role in the overall objective of achieving a general condition of "environmental wellbeing".

In the case top soil diffuse pollution in urban areas, the initial considerations on the probable sources of contaminants and their routes of exposure lead to the identification of some combustion products as the best indicator of the contamination situation and its severity.

In the case examined, the municipality of Trieste, one of the noxious contaminants found is benzo[a]pyrene $\left(\mathrm{C}_{20} \mathrm{H}_{12}\right)$, an aromatic polycyclic hydrocarbon of ascertained carcinogenicity. Thus, this element has been taken as the main indicator of the severity of the situation, area by area.

The choice of the analytes to be used as parameters for the evaluation of the severity of contamination must be supported by some analysis, even in limited number, to confirm their significance and diffusion.

With regard to the spatial extent of the contamination, the Italian legislation does not provide any parameter above which it is possible to consider the case in question as a diffusely polluted site. The only general indication is reported in the above mentioned diffuse pollution guidelines issued by ISPRA, which suggest a minimum value of $1 \mathrm{~km}^{2} .{ }^{86}$

There are also no indications, not even generic, on how to delimit the area involved and its geometric characteristics, because of the varied nature of the sources of pollution both in terms of geometric arrangement and contribution to the phenomenon. Hence, there will generally be no symmetry or ordered spatial collocation for the area affected by diffuse pollution.

${ }^{86}$ ISPRA, supra note 78 at 9. 
The identification of the area affected by diffuse pollution is one of the most difficult aspects to deal with while approaching the problem. In fact, it passes through the hypothesis of possible contaminants sources, but especially of their distribution and their degree of contribution to the phenomenon, as well as through the transport of the substances involved.

Another aspect that must be carefully assessed are the ways people can enter into direct contact with the substances considered. In fact, this factor contributes to the attribution of different risk profiles, which one should consider while scaling the actions to be taken to combat diffuse pollution.

The practical solutions in case of diffuse pollution must therefore evaluate not only contaminants' concentrations, but also their dangerousness linked to the chemical characteristics and the ease with which human beings might interact with them either through contact, ingestion or inspiration.

Routes of exposure are strongly linked to the considered matrix. As for soil, besides skin contact ingestion must also be considered, especially in case of land used for recreational purposes. For some contaminants, the possibility of inhalation must also be taken into consideration.

The above choices of the analytes and the spatial extension allow to formulate a conceptual model, thus formulating initial hypotheses on pollution sources and their possible diffusion pathways. Moreover, they enable the characterization of all micro-areas included within the widespread diffusely polluted area depending on the relative danger, stemming as a combination of several factors such as the nature of the analytes and their concentration. Hence, it is ultimately possible to map out among them those with the greatest probability of human exposure, especially with regard to weakest subjects, such as children and elders.

The development of such model leads to the choice among possible ways of intervention, which often will not consist in a solution based on complete remediation. Instead, it will more generally include a diffuse pollution management system targeted to the reduction of overall risk level, in line with the similar treatment in other fields, such as workplace safety or fire protection.

In other words, in the case of diffuse pollution, the analysis will primarily aim at achieving an acceptable level of risk based on both the potential danger and the actual capacity to solve the problem, thus foregoing the possibility to eliminate the sources of pollution altogether.

\section{Conclusions}

As this article has hopefully made clear, to engage with the issue of diffusely contaminated areas' remediation entails a pioneering endeavour, both on normative and technical grounds. This is even more true when pointing to soil as the object of diffuse pollution, mainly because of the complex and multi-faceted natural functions it might fulfill depending on the geographical context and, perhaps more importantly, its ultimate use and management. 
Nothwithstanding this background, neither EU nor Italian legislation have utterly succeded to deploy a set of regulatory tools capable of addressing diffuse soil pollution in a fully comprehensive manner. In fact, as diffuse pollution might lead to the disruption of numerous soil functions altogether, each threat resulting therefrom shall be dealt with by the relevant instrument aimed at protecting specific natural resources (e.g., water acidification, nitrogen pollution from agriculture, loss of soil biodiversity, etc.). Hence, the interaction between such regulatory tools and diffuse soil pollution is merely indirect, and the degree to which particular soil functions are safeguarded is all but easy to determine. ${ }^{87}$ In this regard, the EU has surely not lived up on its apparently high aspirations on soil protection. ${ }^{88}$

The Italian legislator sought to tackle the issue through a decentralized system, thereby demanding to local authorities the task of shaping and implementing responses to diffuse pollution on their very territory. Such system may indeed prove effective, and ideally spur similar solutions elsewhere. However, as Italian Regions are slowly drafting their DPPs, a uniform benchmark as to the minimal normative and methodological requirements is needed, in order to avert remarkable differences and overall uncertainty as to the scale of remediation options and their (potential) cost for economic operators.

Yet, the experience gained in Europe (and especially in Italy) with contaminated sites allows now to rigorously handle every situation in which the source and the activity causing soil pollution is known. Although such methods cannot be fully mirrored in the context of diffuse pollution, the set of technical knowledge and tools accumulated in the realm of health-environmental risk analysis will certainly prove useful in the shaping of the innovative approach needed to combat diffuse soil pollution.

Hence, it is apparent from this study that the problem of diffuse top soil pollution in urban areas should be addressed in a multidisciplinary fashion, which should include at least the following main aspects:

1. Assessment of pollutants and their dangerousness, above all in relation to the primary use of the soils involved;

2. Formulation of hypothesis on all possible diffuse pollution sources and their respective contribution thereto;

3. Identification of mandatory tools to reduce the emissions of polluting substance(s) and to reduce exposure by the population as much as possible, even with interim initial action, like a ban on access to a pre-determined, diffusely polluted area.

${ }^{87}$ A. Frelih-Larsen et al., supra note 5 at 129.

${ }^{88}$ M. Raffelsiefen \& T. Strassburger, The Protection of Soil: Does the European Union Live up to Its Own Ambitions?, in: H. Ginzky et al. (eds.), International Yearbook of Soil Law and Policy, 2017, p. 389, 408. 
Such methodology is in fact consistent with common modern approaches to increasingly complex problems, thus seeking to provide a complete management of all aspects and possible variables involved, rather than focusing directly on eliminating the source of risk. 